\title{
Hormesis and the radical moderation of law
}

\author{
JB Wiener* \\ Duke Law School and Nicholas School of the Environment, Box 90360, Duke University, Durham, North Carolina \\ 27708-0360
}

Frank Cross's paper on "Legal Implications of Hormesis" offers a provocative starting point for an important discussion. Contrary to the frequent assumption that accepting the evidence of hormesis (benefits at low doses) must invite less stringent regulation, Cross shows that, compared to a linear dose-response relationship, a hormetic (J-shaped) dose-response curve could justify less stringent regulation in some cases, but more stringent regulation in other cases. Hormesis weakens the case for regulation at low exposure levels, because zero exposure would actually entail more harm to public health than some low level of exposure. Cross explains, however, that hormesis also strengthens the case for regulation at high exposure levels, because the benefits of reducing from high to modest exposures could be greater along the hormetic curve than along the linear curve (see Cross' Fig. 3, where $H-H_{2}>H-H_{1}$ ).

These are the first implications of hormesis for regulatory law. But if hormesis is a significant phenomenon, its ultimate implications may be far more radical - and yet radical in a way that counsels moderation. This "radical moderation" would be moderate in policy terms but radical because it forces stark rethinking, even rejection, of some of the core premises of modern regulation.

First, Cross's argument leads to a more general point about setting priorities. Observe that Cross's second result (hormesis warranting more stringent regulation) obtains only where the hormetic curve has a steeper slope than the linear dose-response curve. Where the hormetic curve has a flatter slope than the linear curve - which would be the case as the hormetic curve approaches its nadir (the point Cross refers to as the "tipping point") - then the hormetic curve would justify less stringent regulation

*Correspondence: JB Wiener, Duke Law School and Nicholas School of the Environment, Box 90360, Duke University, Durham, North Carolina 27708-0360 than the linear curve. Where the hormetic curve has a negative slope - which would be the case between zero exposure and the nadir of the curve - then the benefits of more stringent limits on exposure are negative, and would justify relaxing regulation.

These inferences support a more general proposition: the health benefits of any reduction in exposure will vary directly with the slope of the dose-response curve in the relevant range of exposures. This proposition is important whether one accepts the notion of hormesis or not. Regulators are often urged to set risk-based priorities, to tackle the "worst things first." But that advice is incorrect if the dose-response curve is not strictly linear - even if it is monotonically increasing with dose, and has no hormetic (negatively sloped) segment. If some "big" risks (large absolute levels of harm) have flat doseresponse curves near the current exposure (and are steep only near zero exposure), then regulation of those risks might not (initially) accomplish much health protection. Meanwhile, if some "smaller" risks have steep dose-response curves near the current exposure (and are flat below some level of exposure), then regulation of these risks could (initially) accomplish much more health protection. Thus, even apart from hormesis, regulators should not target the "worst things first" - they should target the "most gains first." (Accounting for differences in the cost of control would suggest targeting the "most gains per cost first.”)

Second, hormesis could support more stringent regulation for an entirely different reason. That is because purely "health-based" regulation (ignoring the costs of control), if based on a linear doseresponse extrapolation, may be unconstitutional. The D.C. Circuit has held in the American Trucking case that Congress cannot constitutionally delegate to the EPA the unlimited power to regulate air quality anywhere between current levels and zero; some "limiting principle" must be furnished by EPA to constrain its discretion within that range. ${ }^{1}$ If the Supreme court affirms this holding, EPA will have to come up with some 
such limiting criterion. Hormesis could fit the bill. If EPA regulates to minimize net risks (net of the benefits of low-dose exposures), instead of just picking a number without explaining why it did not pick another number, then EPA may satisfy the courts' test and save the Clean Air Act from unconstitutionality.

This reveals a third point: hormesis is a special case of the more general phenomenon of risk-risk trade-offs. ${ }^{2,3}$ Interventions to reduce a target risk may increase countervailing risks. Airbags both save and kill; so do medicines, foods, pesticides, and hazardous waste cleanups. Hormesis is a special case, in which the very agent that is harmful at high doses is protective at low doses. The more general case includes hormesis as well as trade-offs in which the regulation controls one agent but exacerbates another. Often these riskrisk trade-offs are worthwhile, but sometimes not, and in any case the countervailing risks are often greater than they should be. EPA and other agencies have resisted acknowledging this reality, and have regulated with little or no attention to the countervailing risks of their own risk-prevention efforts (just as private firms can operate with scant attention to the external harms they create). In Corrosion Proof Fittings, the EPA ban on asbestos was struck down in part for its neglect of the risks of highway accidents from inferior brake linings. ${ }^{4}$ In the American Trucking case itself, ${ }^{1}$ the court ruled that EPA had illegally neglected the possibility that its efforts to thin the levels of tropospheric ozone would, while protecting our lungs, put our skin cells at increased risk from ultraviolet radiation. Recognizing these trade-offs could improve the net benefits of regulation, while saving otherwise unbounded statutes from unconstitutionality.

Fourth, if hormesis is significant, it could, as Cross foresees, spur regulation requiring minimum exposures. Against our history of restricting maximum exposures, this seems quite radical. But actually it is quite common, and can be quite moderate. We already require minimum doses of fluoride and chlorine in public drinking water, knowing that these substances pose harms at high doses but also that they offer significant public health benefits at low doses. Likewise, we mandate that children receive numerous vaccines, even though some of these vaccines pose risks. Ditto dental X-rays. And sometimes we set minimum highway speeds as well as maximum speed limits, where a uniform intermediate speed level is safer than either a high or a low speed. Many pollution laws can also be understood as imposing exposure minima: laws setting ambient concentrations limits, emissions limits, re- quiring specific pollution control technology, and halting regulation at the limit of industrial feasibility, all implicitly oblige the public to be exposed in the short term to the residual discharges that the government binds itself not to regulate. (As Cross points out, the feasibility criterion is flawed where it allows higher levels of pollution than would be justified under cost-benefit criteria; the feasible level would match the hormetic nadir only by coincidence.) If hormesis is significant, some current environmental laws could be interpreted to enable the government to set formal minima as well as maxima. Section 109 of the Clean Air Act tells EPA to "protect the public health with an adequate margin of safety." IF (a big if) EPA decides that some minimum concentration levels are needed to "protect the public health ..." (for example, to screen out ultraviolet radiation), the language of the Act does not seem to bar that approach.

Fifth, hormesis redefines our notion of "pollution" and "contamination." It questions the premise that "pollutants" are unmitigated bads. This is radical because modern environmentalism is built in large part on the dichotomies of good versus evil, clean versus dirty, natural versus unnatural. ${ }^{5}$ Substances are placed on lists of bads, as under section 112 of the Clean Air Act. In American Trucking, EPA's brief explained that it had ignored the ultraviolet-screening benefits of ozone because it thought "pollutants" could only have adverse effects. ${ }^{6}$ Zero discharge is the express goal of the Clean Water Act, and of many who advocate the "precautionary principle." Hormesis challenges these premises. Paracelsus taught us long ago that the dose, not the substance, makes the poison. And common sense teaches us that a little bit can be good for us even though a lot would be bad: vitamins, minerals, medicines, wine, salt, toothpaste, oxygen, sunshine - almost everything (perhaps even law for society, and humans for the earth). In short, moderation is a virtue. Thus hormesis points to the "radical moderation" of risk regulation. This can be consonant with the values of environmentalism: think "small is beautiful," and insert "dose."

The most radical implication of hormesis and riskrisk trade-offs is the deradicalization of environmental discourse. Things are not either bad or good: they are both. The world is not a simple battle between good and evil: it is a series of complex trade-offs among competing goods, and among countervailing risks. The hard question is not whether something is bad or good, it is how much is too much or too little; it is finding the point of optimality amidst risks on all sides. The regime we now have is too often radical in its stark dichotomies; the future may be radical in its moderation. 


\section{References}

1 American Trucking Associations v. US EPA. 1999. 175 F.3d 1027 (D.C. Cir.) .

2 Graham JD, Wiener JB. Risk versus Risk: Tradeoffs in Protecting Health and the Environment. Harvard University Press, Cambridge, 1995.

3 Wiener JB. Managing the iatrogenic risks of risk management. Risk: Health Saf Environ 1998; 9: 39-82.
4 Corrosion Proof Fittings v. US EPA. 1991. 947 F.2d 1201 (5th Cir.).

5 Wiener JB. Beyond the balance of nature. Duke Environ Law Policy Forum 1996; 7: 1-24.

6 Brief of Respondent US EPA in American Trucking Associations v. US EPA. 1998. D.C. Cir., No. 97-1441 (filed June 22, 1998), pp. 58-60, 62. 